\title{
Selective cannabis strain allergy in a patient presenting with a local allergic reaction
}

\author{
Peter Stepaniuk * (1) and Amin Kanani
}

\begin{abstract}
Background: Cannabis use is growing domestically due to recent legalization in many jurisdictions. There are two main species of cannabis, Cannabis sativa and Cannabis indica, and thousands of different commercially available cannabis strains. Although there are multiple reports of cannabis allergy in the literature, to our knowledge, there is no prior published report of selective cannabis strain allergy.

Case presentation: A 31-year-old male was referred for allergy assessment due to several episodes of localized pruritus and erythema after direct contact with various strains of cannabis. He had noted that the severity of his reaction appeared to be strain dependent. He developed a severe local reaction involving bilateral periorbital edema shortly after coming into direct contact with one particular strain of cannabis. He denied any adverse symptoms after inhalation of cannabis. Fresh skin prick testing was performed to various strains of cannabis and had positive testing to the three of the five tested strains.

Conclusions: We believe this is the first reported case of selective cannabis strain allergy based on patient history and skin prick testing. This case report outlines the variability in different strains of cannabis and stresses the importance of further research into cannabis allergen identification. Multiple cannabis allergens should be included and incorporated into commercial extracts when they become routinely available.
\end{abstract}

Keywords: Cannabis, Marijuana, Strain, Allergy, Indica, Sativa, Hybrid, Phylogeny, Taxonomy

\section{Background}

Cannabis use is prevalent across the world. In response to recent legalization in many jurisdictions, more information regarding potential adverse events are becoming evident. The three main species of cannabis are Cannabis sativa, Cannabis indica and Cannabis ruderalis. C. indica and C. sativa are more commonly used for their medicinal effects, and it is believed that all current commercially available strains are descendants of these two species [1]. New cannabis strains are produced by crossbreeding existing strains to take advantage of particular drug effects and a hybrid strain is considered to contain components of both $C$. indica and C. sativa. There are nearly 3000 different strains listed on some commercial websites which are organized into three dominant classes (Indica, Sativa, Hybrid) [2]. The cannabis plants are part of the family Cannabaceae and order Rosales, and are phylogenetically more closely related to common allergenic trees (specifically Hops, Mulberry and Elm), as opposed to other common allergenic plants (e.g., grasses and weeds) [3, 4] (Fig. 1). Various studies have linked cannabis use to hypersensitivity reactions including exacerbations of asthma, allergic rhinitis, contact dermatitis, anaphylaxis and urticaria [6-9]. However, on review of the literature, there have not been any reports of selective cannabis strain allergy that we could identify.

*Correspondence: peter.stepaniuk@alumni.ubc.ca

Division of Allergy and Immunology, Department of Medicine, University

of British Columbia, 905-750 Broadway W, Vancouver, BC V5Z 1H8, Canada

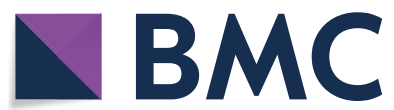

(c) The Author(s) 2021. This article is licensed under a Creative Commons Attribution 4.0 International License, which permits use, sharing, adaptation, distribution and reproduction in any medium or format, as long as you give appropriate credit to the original author(s) and the source, provide a link to the Creative Commons licence, and indicate if changes were made. The images or other third party material in this article are included in the article's Creative Commons licence, unless indicated otherwise in a credit line to the material. If material is not included in the article's Creative Commons licence and your intended use is not permitted by statutory regulation or exceeds the permitted use, you will need to obtain permission directly from the copyright holder. To view a copy of this licence, visit http://creativeco mmons.org/licenses/by/4.0/. The Creative Commons Public Domain Dedication waiver (http://creativecommons.org/publicdomain/ zero/1.0/) applies to the data made available in this article, unless otherwise stated in a credit line to the data. 


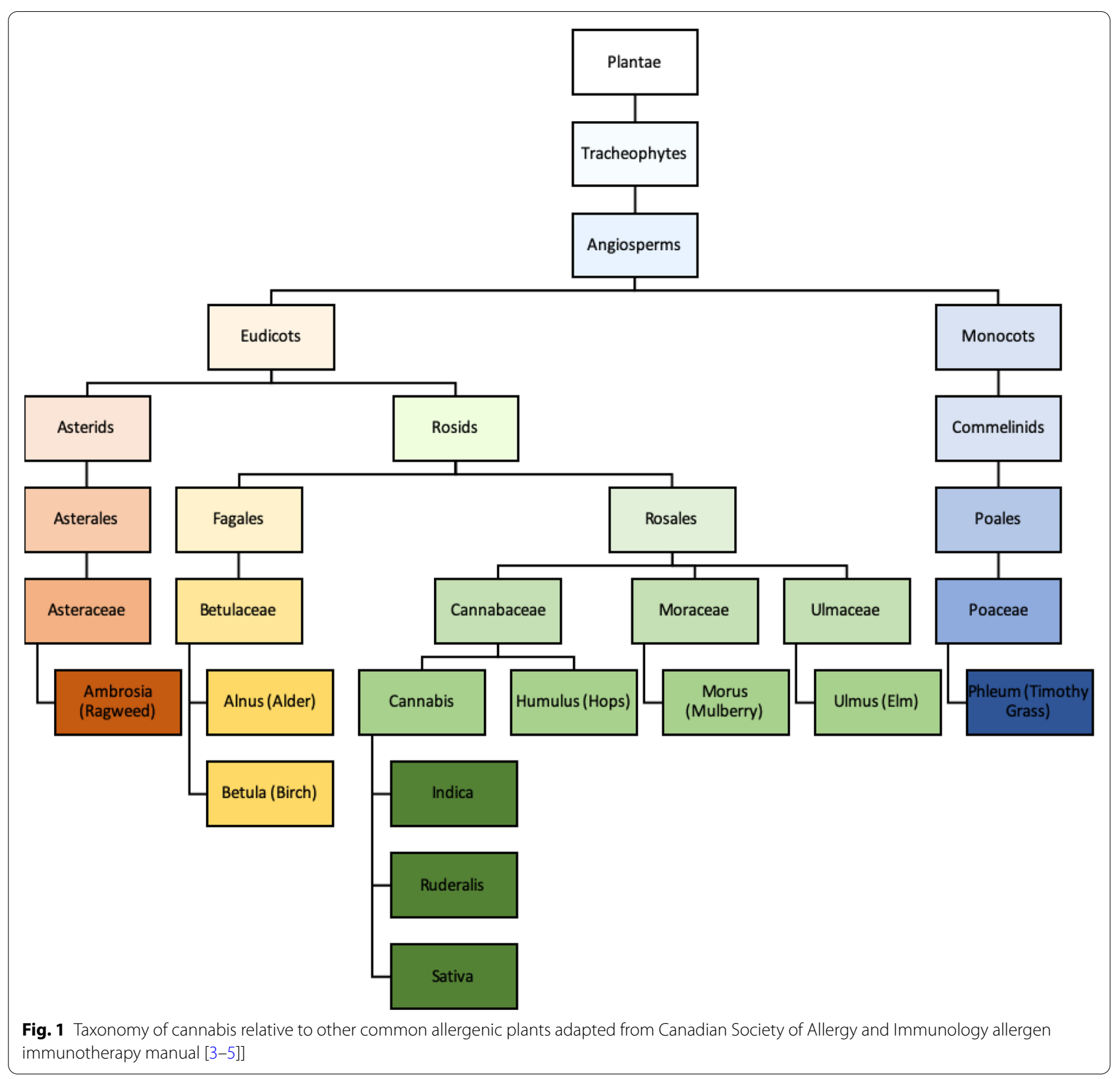

\section{Case presentation}

A 31-year-old male was referred to our community allergy practice for assessment of suspected cannabis allergy. He had previously experienced several episodes of localized pruritus and erythema after direct contact with various strains of cannabis and noted that the severity of his reaction appeared to be strain dependent. He had developed a severe local reaction involving bilateral periorbital edema shortly after coming into direct contact with one particular strain of cannabis (believed to be Blue Moonshine, but patient uncertain). This particular episode was also associated with dyspnea in the absence of any other systemic symptoms. For this reaction he presented to a local emergency department and was treated with antihistamines and corticosteroids with good effect. He had never had an immediate reaction after smoking cannabis. After this particular episode and prior to his allergy consultation, he continued to smoke cannabis without adverse reaction but tried to avoid direct contact, particularly with his mucous membranes. His past medical history was notable for asthma and seasonal rhinoconjunctivitis.

The patient was diagnosed with recurrent local allergic reactions after direct contact with cannabis and he 
had a suspected selective cannabis strain allergy based on his clinical history. Skin testing was performed to environmental inhalants and the patient had positive reactions to dust mite, grass pollens and various tree pollens. The patient also brought in multiple strains of cannabis for skin testing including "Blue Moonshine" (Cannabis indica dominant strain), "Blue Dream" (Hybrid strain that is largely Cannabis sativa dominant), "Sweet Island Skunk" (Cannabis sativa dominant strain), "Sweet Skunk" (Hybrid) and "Blueberry Haze" (Hybrid). The cannabis strains where mixed with small aliquots of water for skin testing. Fresh testing was required due to the absence of commercially available abstracts. He had positive testing to the strains "Blue Dream" (7 mm), "Sweet Island Skunk" (10 mm) and "Blueberry Haze" (6 $\mathrm{mm}$ ) while he had negative testing to "Blue Moonshine" and "Sweet Skunk" (Table 1). Histamine and saline controls were appropriate ( $3 \mathrm{~mm}$ and $0 \mathrm{~mm}$ respectively).

The patient was advised to avoid direct cutaneous or mucosal contact with cannabis due to his reported clinical history and skin testing. Due to the inconsistences in strain identification by history and skin testing, he was advised to avoid all strains. An epinephrine autoinjector was prescribed in case he developed a more severe systemic reaction on repeat exposure. A telephone follow-up visit was conducted 6 months after the initial consultation. The patient endorsed that he was still smoking cannabis regularly but had not had any new significant reactions. He continued to use all above tested strains of cannabis in addition to a few new ones. He was still avoiding direct cutaneous and mucosal contact as much as possible.

\section{Discussion and conclusions}

Despite the fact that all current strains of cannabis are believed to be descendants of two plant species, there is immense variability amongst commercially available strains. This patient had positive testing to three of five strains he was tested against, and he appeared to be more sensitized to Sativa dominant strains (Sweet

Table 1 Results of patient skin testing to select cannabis strains

\begin{tabular}{ll}
\hline Cannabis strain & $\begin{array}{l}\text { Skin prick } \\
\text { test size of } \\
\text { wheal }\end{array}$ \\
\hline Blueberry haze $(H)$ & $6 \mathrm{~mm}$ \\
Blue dream (H/S) & $7 \mathrm{~mm}$ \\
Blue moonshine (I) & $0 \mathrm{~mm}$ \\
Sweet island skunk (S) & $10 \mathrm{~mm}$ \\
Sweet skunk (H) & $0 \mathrm{~mm}$ \\
\hline
\end{tabular}

$H$ hybrid, SC. sativa dominant strain, IC. indica dominant strain
Island Skunk, Blue Dream) as opposed to Indica dominant strains (Blue Moonshine). However, these results were inconsistent with the patient's history as he believed that Blue Moonshine was the strain responsible for his prior severe local allergic reaction. We believe this is the first reported case of selective cannabis strain allergy based on patient history and skin prick testing.

There are currently only two allergens (Can s 3 and Can s 4) listed in the WHO/IUIS Allergen Nomenclature Sub-committee, and they were both identified in $C$. sativa. There are currently no known allergens of Cannabis indica listed in the database. It is estimated that only $72 \%$ of patients with a reported allergy to cannabis are sensitized to Can s 3 [10]. Published data is not currently available regarding the allergenicity of Can s 4 . One study looking at genotyping of various cannabis strains showed that C. sativa and $C$. indica have distinguishable pools of genetic diversity and there is only a moderate correlation between the genetic structure of marijuana strains and their reported $C$. sativa and $C$. indica ancestry [11]. In addition, the immense amount of cross-breeding of different strains, and large number of strains currently commercially available, makes genetic analysis of cannabis plants difficult. With rising use of cannabis, the ability to accurately detect individuals with cannabis allergy on skin prick testing is important in order to reduce hypersensitivity reactions.

In the near future, cannabis extracts will likely be available for clinical use. As there are currently only two confirmed allergens from cannabis plants (both derived from $C$. sativa), this report also emphasizes the importance of further research into determining the specific allergens implicated in cannabis allergy. Having a larger number of identified allergens available will likely increase the specificity of testing. Accurate identification of cannabis allergens and incorporation into commercial extracts will undoubtedly be a difficult task given the complexity and variability of currently available commercial strains.

Acknowledgements

Not applicable.

\section{Authors' contributions}

PS engaged in background research on the subject and was a major

contributor in writing the manuscript. AK oversaw the care of the patient and reviewed the submitted manuscript. All authors read and approved the final manuscript.

Funding

No formal funding was obtained for this study.

Availability of data and materials

Not applicable. 


\section{Declarations}

Ethics approval and consent to participate

Not applicable.

\section{Consent for publication}

Patient consent was obtained for publication.

\section{Competing interests}

The authors declare that they have no competing interests.

Received: 12 January 2021 Accepted: 3 May 2021

Published online: 17 May 2021

\section{References}

1. Russo EB. History of cannabis and its preparations in saga, science, and sobriquet. Chem Biodivers. 2007;4(8):1614-48.

2. Leafy Staff. Cannabis Strain Explorer Seattle, WA, USA: Leafly Holdings, Inc; 2021. Available from: https://www.leafly.ca/strains. Accessed 9 May 2021.

3. Oh H, Seo B, Lee S, Ahn DH, Jo E, Park JK, et al. Two complete chloroplast genome sequences of Cannabis sativa varieties. Mitochondrial DNA A DNA Mapp Seq Anal. 2016:27(4):2835-7.

4. McPartland JM. Systematics at the levels of family, genus, and species. Cannabis Cannabinoid Res. 2018;3(1):203-12
5. Kim H, Moote W, Waserman S. Immunotherapy Manual: Canadian Society of Allergy \& Clinical Immunology; 2016. Available from: https://csaci. ca/wp-content/uploads/2017/12/IT-Manual-2016-5-July-2017-rev.pdf. Accessed 9 May 2021.

6. Bramness JG, von Soest T. A longitudinal study of cannabis use increasing the use of asthma medication in young Norwegian adults. BMC Pulm Med. 2019;19(1):52.

7. Saleem N, Waqar S, Shafi A. Skin prick test reactivity to common aeroallergens among allergic rhinitis patients. J Coll Physicians Surg Pak. 2018;28(10):766-71.

8. Foster E, Nguyen C, Norris P. Contact buzz: allergic contact dermatitis to cannabis. Dermatitis. 2018;29(4):223-4.

9. Silvers WS, Bernard T. Spectrum and prevalence of reactions to marijuana in a Colorado allergy practice. Ann Allergy Asthma Immunol. 2017;119(6):570-1.

10. Decuyper II, Van Gasse AL, Faber MA, Elst J, Mertens C, Rihs HP, et al. Exploring the diagnosis and profile of cannabis allergy. J Allergy Clin Immunol Pract. 2019;7(3):983-9.e5.

11. Sawler J, Stout JM, Gardner KM, Hudson D, Vidmar J, Butler L, et al. The genetic structure of marijuana and hemp. PLoS ONE. 2015;10(8):e0133292.

\section{Publisher's Note}

Springer Nature remains neutral with regard to jurisdictional claims in published maps and institutional affiliations.
Ready to submit your research? Choose BMC and benefit from:

- fast, convenient online submission

- thorough peer review by experienced researchers in your field

- rapid publication on acceptance

- support for research data, including large and complex data types

- gold Open Access which fosters wider collaboration and increased citations

- maximum visibility for your research: over 100M website views per year

At BMC, research is always in progress.

Learn more biomedcentral.com/submissions 